\title{
COMPARISON OF ULTRASONIC PULSE VELOCITY TEST RESULTS WITH AND WITHOUT USING TRANSDUCER STABILIZER
}

\author{
Fajar Surya Herlambang ${ }^{1, *)}$, Evin Yudhi Setyono ${ }^{2)}$ \\ ${ }^{1,2)}$ Civil Engineering Department of Bali State Polytechnic \\ Jl. Kampus, Bukit Jimbaran, Badung Selatan, Bali, Indonesia \\ ${ }^{*}$ Email: fajarjtspnb@gmail.com
}

\begin{abstract}
Some research on the Ultrasonic Pulse Velocity (UPV) test has not covered much about the problems encountered during the data collection process. Based on experience using UPV test equipment, it is known that instability occurs in reading the test results. This is caused by the inability of the operator, in maintaining the stability of the transducer both in its position and pressure, especially in the measurement with the overhead position. Therefore, in this study a tool was made to make the transducer stable in the test position. Comparison of measurement results shows that, the uncertainty of wave velocity measurement decreases from the range of $4 \%-17 \%$ to $0.2 \%-0.4 \%$. Meanwhile, the uncertainty of measurement of wave travel time decreased from the range of $0.8 \%-14 \%$ to $0.1 \%-0.4 \%$. This can be interpreted that, the level of accuracy of measurements using a transducer stabilizer is $99.6 \%-99.9 \%$. Thus, the use of transducer stabilizers is believed to be able to improve measurement accuracy.
\end{abstract}

Keywords : UPV, transducer, stability

\section{INTRODUCTION}

There are 2 types of testing methods used to evaluate the characteristics of a material, namely destructive test and non-destructive test. Both types of testing have their respective strengths and weaknesses. Destructive testing gives more factual results, but if carried out on a building it will be feared to affect the strength of its structure. Non-destructive testing (NDT) is an examination, test, or evaluation performed on any type of test object without changing or altering that object in any way, in order to determine the absence or presence of conditions or discontinuities that may have an effect on the usefulness or serviceability of that object (Hellier, 2003). Ultrasonic Pulse Velocity (UPV) test as a testing of nondestructive methods, has been widely used to evaluate concrete quality. Ultrasonic waves are used in testing of a concrete, by transmitting wave signals with a frequency of 20-150 $\mathrm{kHz}$ on the concrete surface. The ultrasonic pulse velocity (UPV) method is based on measurement of the travel time of an ultrasonic wave through concrete over a known path length. The commercially available systems consist of two piezoelectric transducers and electronic circuitry to determine the pulse travel time between the transducers (Dilek, 2009). 
According to Woodson (2009), UPV has many advantages including:

a. provides a nondestructive method for evaluating structures,

b. measures the time of travel of acoustic pulses of energy through a material of known thickness,

c. piezoelectric transducers are housed in metal casings and are excited by high-impulse voltages as they transmit and receive acoustic pulses,

d. an oscilloscope in the system measures time and displays acoustic waves,

e. reliable in situ delineations of the extent and severity of cracks, areas of deterioration, and general assessments,

f. capable of penetrating up to 300 feet of continuous concrete with the aid of amplifiers,

g. can be transported easily,

h. has a high data acquisition to cost ratio,

i. can be converted for underwater use.

The UPV method used to examine the homogeneity and quality of concrete is based on propagation of high-frequency sound wave through the material (Singh, 2018). Jepriani (2008), provides accuracy of measurement of concrete cracks in the transducer distance variation of $15.41 \%$ - $124.09 \%$. Herlabang, et al (2017), estimated the depth of concrete cracks with variations in transducer distance and type of reinforcement, with accuracy obtained ranging from $13 \%$ to $92 \%$. Transducers play an important role in ultrasonic measurements and affects accuracy.

Besides having many advantages, UPV is also has weaknesses. Because of its sensitivity of this method, caution is needed in the transducer placement. The accuracy of the UPV test results is affected by the placement of the transducer during the measurement. The precise and stable position of the transducer will result in a valid reading of the data. Transducer instability, mainly caused by the operator's inability to hold the transducer position, and also the fatigue factor caused by repeated testing. Testing conditions are increasingly difficult when conducting overhead tests where the operator must look up and while trying to maintain the transducer position. Corrections of the UPV test results due to instability of the transducer, have been carried out by Budio, et al (2016). In one type of specimen, the wave velocity read on a UPV device has a wide spread of data. This shows the inconsistency of the reading caused by the unstable position of the transducer. Although the final conclusions of the study did not produce a correction formula.

Based on the description above, measurement accuracy is related to transducer placement. A transducer stabilizer will be able to maintain the position of the transducer during measurement, especially in tests with an overhead test position for a long period of time. A good and stable contact transducer on the surface of the test concrete is expected to provide accurate measurement results. The 
purpose of this study is to compare the results of UPV test measurements with and without the use of a transducer stabilizer.

\section{RESEARCH METHODS}

This study compares the reading of the wave velocity and time of the UPV device, with and without the use of a transducer stabilizer. The type of UPV tool used is NDT James Instrument VMeter MK IV (Figure 1).

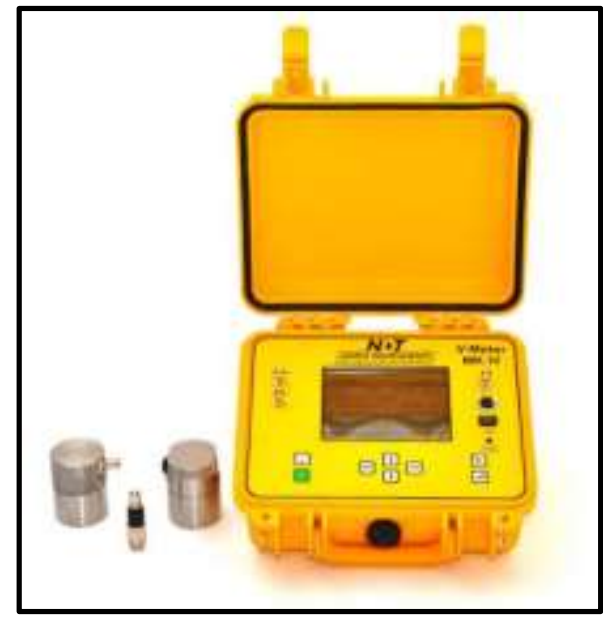

Figure 1. NDT James Instrument V-Meter MK IV

There are three basic ways in which the transducers may be arranged, as shown in Figure 2, these are: direct transmission, semi-direct transmission, and indirect transmission. In direct method (figure 2a), the path is clearly defined and can be measured accurately, it is the most reliable from the point of view of transit time measurement. This setting is recommended used wherever possible for assessing concrete quality. The semi-direct method (figure $2 b$ ) can sometimes be used satisfactorily if the angle between the transducers is not too great, and if the path length is not too large (Bungey, et al, 2006). The attenuation of the transmitted pulse sometimes makes no clear signal received. The path length is also less clearly defined, but it is generally regarded to measure this from centre to centre of transducer faces. It makes the semi-direct transmission is less effective than direct method. The indirect method (figure 2c) is definitely the least satisfactory compare to previous method. The exact path length is uncertain. Both transducers is placed on same surface in a certain distance. The transmitter will receive signal that will be predominantly influenced by the surface concrete, which may not be representative of the body. This method is dependent upon scattering of the pulse by discontinuities and the pulse velocity. 


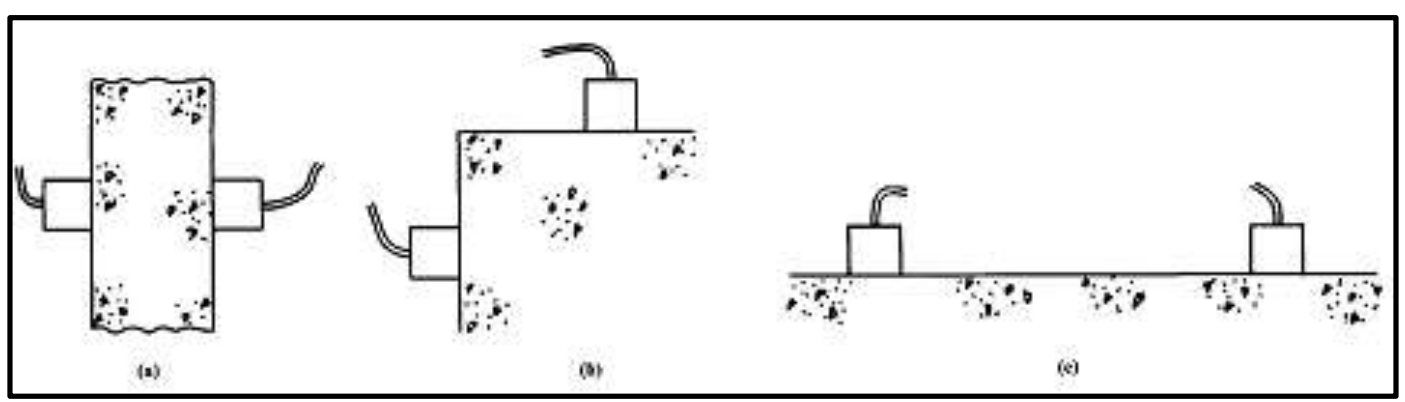

Figure 2. UPV test method

These three methods will be used in this study together with a transducer stabilizer. The transducer stabilizer is a self-designed, made of acrylic material with a thickness of 8 $\mathrm{mm}$. A pair of iron clamps were added as a lock. The holes in the acrylic plane, have the same diameter as the diameter of the transducer used. The distance between the center of the hole is designed to be $10 \mathrm{~cm}$ (Figure 3). The distance setting is based on the results of previous studies (Herlambang, et al, 2017), that the best accuracy of $92.07 \%$ is obtained at a transducer distance of $10 \mathrm{~cm}$.

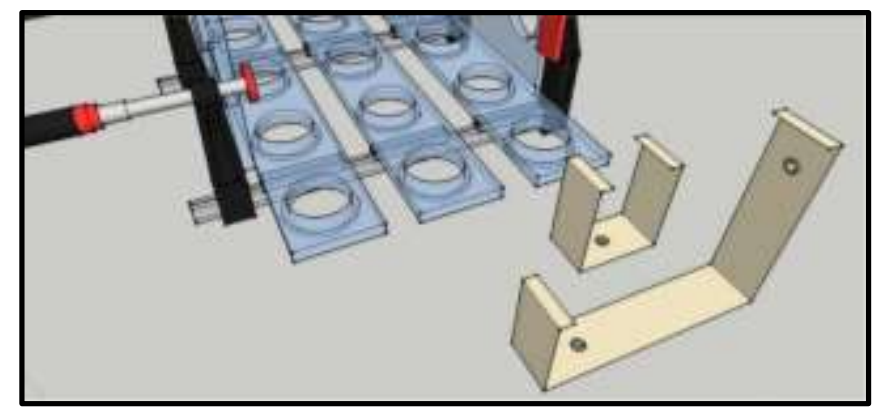

Figure 3. Design of a transducer stabilizer
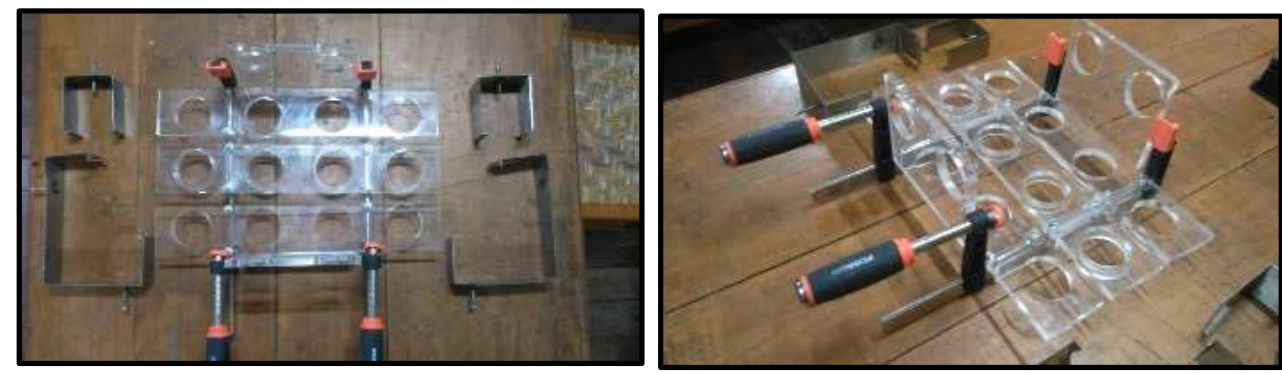

Figure 4. Transducer stabilizer

In this study, the design of the device was not yet perfect, but the application of the idea was felt to provide stability to the transducer. Some weaknesses that are still felt when using this tool are: practical loading and unloading so that it still takes quite a long time in the settings, still has a fairly heavy weight so that it is quite tired in loading, and still in the form of 3 separate elements that can 
still be put together to achieve a better level of practicality (Figure 4).

The test sample is the structure of "bale bengong" at the Bali State Polytechnic campus. Measurements were made 30 times for each test position, direct test, semi-direct test, and indirect test. The installation of the transducer stabilizer on the beam, in the overhead test position and the indirect test method can be seen in Figure 5. The two transducers are placed on the bottom of the beam, and locked to the stabilizer.

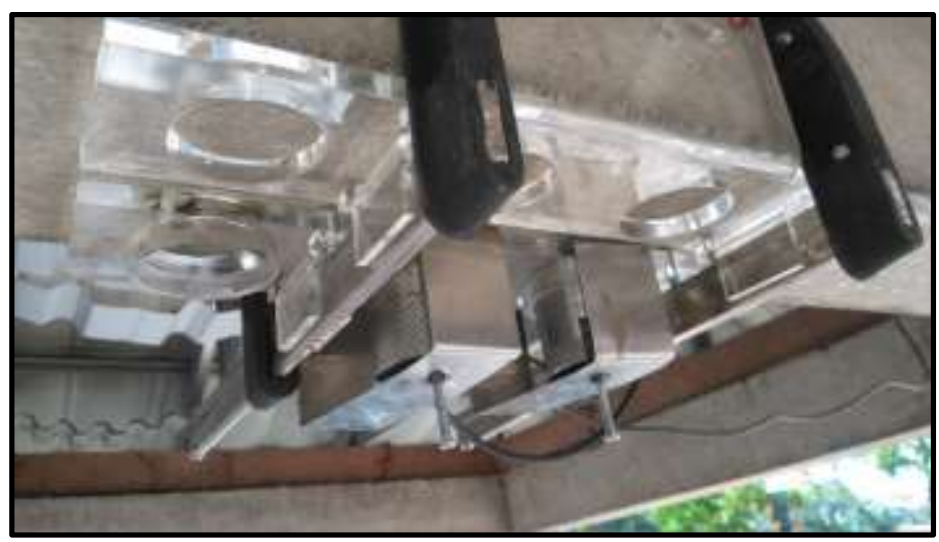

Figure 5. Installation of transducer on the stabilizer

Next, the value of the wave velocity and time are analysed descriptively to obtain the average value and the standard deviation. Both statistical parameters will later become indicators of the stability of the measurement data. Relative uncertainty (RU) is a comparison between absolute uncertainty and measurement results $(\Delta x / x)$ and expressed in percent (\%). The smaller the relative uncertainty, the higher the accuracy achieved in the measurement (Riskawati, et al, 2018).

\section{RESULTS AND DISCUSSION}

The data obtained are propagation velocity $(v)$ and ultrasonic wave travel time $(T)$ generated from the test without and with a transducer stabilizer. From 30 measurements, the data shown in Table 1 and 2 are obtained.

Table 1. Measurement results without transducer stabilizers

\begin{tabular}{ccccccc} 
Number & \multicolumn{5}{c}{ Test Method } \\
\cline { 2 - 7 } of Test & \multicolumn{2}{c}{ direct } & \multicolumn{2}{c}{ semi-direct } & \multicolumn{2}{c}{ indirect } \\
\cline { 2 - 7 } & $v(\mathrm{~m} / \mathrm{s})$ & $T(\mu \mathrm{s})$ & $v(\mathrm{~m} / \mathrm{s})$ & $\mathrm{T}(\mu \mathrm{s})$ & $v(\mathrm{~m} / \mathrm{s})$ & $T(\mu \mathrm{s})$ \\
\hline 1 & 3082 & 50.3 & 2591 & 32.8 & 1038 & 96.3 \\
2 & 3100 & 50.0 & 2615 & 32.5 & 1095 & 75.7 \\
3 & 3125 & 49.6 & 2623 & 32.4 & 1495 & 69.2 \\
4 & 3110 & 49.7 & 2640 & 32.2 & 1792 & 55.8 \\
5 & 3131 & 49.5 & 2632 & 32.3 & 1792 & 55.8 \\
\hline
\end{tabular}




\begin{tabular}{ccccccc}
6 & 3144 & 49.3 & 2648 & 32.1 & 1805 & 55.4 \\
7 & 3150 & 49.2 & 2656 & 32.0 & 1825 & 54.8 \\
8 & 3157 & 49.1 & 2681 & 31.7 & 1821 & 54.9 \\
9 & 3157 & 49.1 & 2665 & 31.9 & 1835 & 59.5 \\
10 & 3150 & 49.0 & 2665 & 31.9 & 1838 & 54.4 \\
11 & 3163 & 48.9 & 2673 & 31.8 & 1855 & 53.9 \\
12 & 3170 & 49.3 & 2681 & 31.7 & 1852 & 54.0 \\
13 & 3157 & 49.0 & 2964 & 32.2 & 1873 & 53.4 \\
14 & 3150 & 48.9 & 2648 & 32.1 & 1859 & 53.8 \\
15 & 3163 & 49.1 & 2640 & 32.2 & 1862 & 53.7 \\
16 & 3170 & 49.2 & 2673 & 31.8 & 1855 & 53.9 \\
17 & 3176 & 49.0 & 2693 & 31.5 & 1736 & 57.5 \\
18 & 3183 & 48.9 & 2707 & 31.4 & 1736 & 57.3 \\
19 & 3183 & 48.8 & 2716 & 31.3 & 1739 & 57.5 \\
20 & 3163 & 48.7 & 2724 & 31.2 & 1748 & 57.2 \\
21 & 3176 & 48.7 & 2778 & 30.6 & 1751 & 57.1 \\
22 & 3183 & 49.0 & 2824 & 30.1 & 1616 & 61.9 \\
23 & 3176 & 48.8 & 2872 & 29.6 & 1672 & 59.8 \\
24 & 3170 & 48.7 & 2981 & 29.4 & 1667 & 60.0 \\
25 & 3183 & 48.8 & 2921 & 29.1 & 1715 & 58.3 \\
26 & 3163 & 48.9 & 2911 & 29.2 & 1712 & 58.4 \\
27 & 3176 & 48.8 & 2901 & 29.3 & 1721 & 58.1 \\
28 & 3170 & 48.9 & 2911 & 29.2 & 1727 & 57.0 \\
29 & 3176 & 48.8 & 2921 & 29.1 & 1730 & 57.8 \\
30 & 3176 & 48.8 & 2962 & 28.7 & 1736 & 57.6 \\
\hline$\Sigma$ & 91934.000 & 1472.80 & 82517.000 & 933.300 & 51498.000 & 1770.000 \\
\hline mean & 3064.467 & 49.093 & 2750.567 & 31.110 & 1716.600 & 59.000 \\
\hline SD & 520.591 & 0.389 & 127.106 & 1.291 & 195.449 & 8.429 \\
\hline RU & $\mathbf{1 6 . 9 8 8}$ & $\mathbf{0 . 7 9 1}$ & $\mathbf{4 . 6 2 1}$ & $\mathbf{4 . 1 4 9}$ & $\mathbf{1 1 . 3 8 6}$ & $\mathbf{1 4 . 2 8 6}$ \\
\hline & & & & & & \\
\hline & 319.9 &
\end{tabular}

Based on Table 1, it can be seen that the results of wave velocity measurements in UPV settings without transducer stabilizers produce a relative uncertainty (RU) of $4 \%-16 \%$, while for wave travel time is $0.7 \%$ $14 \%$. The percentage of measurement relative uncertainty can be used as an indicator in seeing the stability of the instrument reading. The instability of instrument reading is expected to arise due to the fatigue factor of the instrument operator, so the position of the receiving transducer often shifts and affects the UPV reading.

To overcome this, the transducer stabilizer is designed to hold the position of the receiving transducer at the position of the test point. The test results show an increase in the stability of the instrument readings as shown in Table 2 below. In the measurement of propagation velocity and wave travel time, the percentage of uncertainty is $0.1 \%$ $0.4 \%$. 
Table 2. Measurement results with transducer stabilizers

\begin{tabular}{ccccccc}
\hline \multirow{2}{*}{$\begin{array}{c}\text { Number } \\
\text { of Test }\end{array}$} & \multicolumn{5}{c}{ Test Method } \\
\cline { 2 - 7 } & \multicolumn{2}{c}{ direct } & \multicolumn{2}{c}{ semi-direct } & \multicolumn{2}{c}{ indirect } \\
\cline { 2 - 7 } & $v(\mathrm{~m} / \mathrm{s})$ & $T(\mu \mathrm{s})$ & $v(\mathrm{~m} / \mathrm{s})$ & $T(\mu \mathrm{s})$ & $v(\mathrm{~m} / \mathrm{s})$ & $T(\mu \mathrm{s})$ \\
\hline 1 & 3144 & 49.3 & 3114 & 27.3 & 1802 & 55.5 \\
2 & 3144 & 49.3 & 3125 & 27.2 & 1805 & 55.4 \\
3 & 3144 & 49.3 & 3137 & 27.1 & 1805 & 55.4 \\
4 & 3140 & 49.2 & 3125 & 27.2 & 1802 & 55.5 \\
5 & 3157 & 49.1 & 3137 & 27.1 & 1802 & 55.5 \\
6 & 3150 & 49.2 & 3125 & 27.2 & 1802 & 55.5 \\
7 & 3157 & 49.1 & 3148 & 27.0 & 1805 & 55.4 \\
8 & 3144 & 49.3 & 3137 & 27.1 & 1808 & 55.3 \\
9 & 3144 & 49.3 & 3148 & 27.0 & 1805 & 55.4 \\
10 & 3150 & 49.2 & 3160 & 26.9 & 1805 & 55.4 \\
11 & 3150 & 49.2 & 3137 & 27.1 & 1808 & 55.0 \\
12 & 3150 & 49.2 & 3148 & 27.0 & 1808 & 55.3 \\
13 & 3138 & 49.4 & 3148 & 27.0 & 1812 & 55.2 \\
14 & 3150 & 49.2 & 3148 & 27.0 & 1808 & 55.3 \\
15 & 3150 & 49.2 & 3137 & 27.1 & 1818 & 55.0 \\
16 & 3150 & 49.1 & 3148 & 27.0 & 1815 & 55.1 \\
17 & 3144 & 49.3 & 3148 & 27.0 & 1808 & 55.3 \\
18 & 3138 & 49.2 & 3172 & 26.8 & 1815 & 55.1 \\
19 & 3157 & 49.2 & 3148 & 27.0 & 1808 & 55.3 \\
20 & 3144 & 49.3 & 3137 & 27.1 & 1815 & 55.2 \\
21 & 3150 & 49.2 & 3148 & 27.0 & 1808 & 55.3 \\
22 & 3144 & 49.2 & 3148 & 27.0 & 1812 & 55.1 \\
23 & 3150 & 49.3 & 3160 & 26.9 & 1808 & 55.3 \\
24 & 3138 & 49.2 & 3160 & 26.9 & 1815 & 55.0 \\
25 & 3150 & 49.4 & 3148 & 27.0 & 1808 & 55.2 \\
26 & 3150 & 49.2 & 3160 & 26.9 & 1818 & 55.3 \\
27 & 3150 & 49.2 & 3160 & 26.9 & 1812 & 55.2 \\
28 & 3144 & 49.3 & 3160 & 26.9 & 1808 & 55.1 \\
29 & 3150 & 49.2 & 3160 & 26.9 & 1812 & 55.3 \\
30 & 3150 & 49.3 & 3160 & 26.9 & 1808 & 55.3 \\
\hline$\Sigma$ & 94421.000 & 1477.1 & 94391.000 & 810.5 & 54265.000 & 1658.20 \\
\hline mean & 3147.367 & 49.237 & 3146.367 & 27.01 & 1808.833 & 55.273 \\
\hline SD & 5.236 & 0.076 & 13.283 & 0.11 & 4.654 & 0.151 \\
\hline RU & $\mathbf{0 . 1 6 6}$ & $\mathbf{0 . 1 5 5}$ & $\mathbf{0 . 4 2 2}$ & $\mathbf{0 . 4 2}$ & $\mathbf{0 . 2 5 7}$ & $\mathbf{0 . 2 7 3}$ \\
\hline & & & & & &
\end{tabular}

Table 3 below shows the relatively small percentage of error value indicates that the measurement using a transducer stabilizer is capable of producing accuracy of $99.6 \%$ - 99.9\%. This stable data recording is expected to improve measurement accuracy. 
Table 3. Comparison of measurement relative uncertainty (\%)

\begin{tabular}{lcccccc}
\hline \multirow{2}{*}{ Data } & \multicolumn{2}{c}{ direct test } & \multicolumn{2}{c}{ semi-direct test } & \multicolumn{2}{c}{ indirect test } \\
\cline { 2 - 7 } & with & without & with & without & with & without \\
\hline Velocity & 16.988 & 0.166 & 4.621 & 0.422 & 11.386 & 0.257 \\
Time & 0.791 & 0.155 & 4.149 & 0.425 & 14.286 & 0.273 \\
\hline
\end{tabular}

\section{CONCLUSIONS}

The use of transducer-receiver stabilizers has been shown to increase measurement accuracy by increasing measurement accuracy and reducing the relative error rate in measuring wave velocity and wave travel time.

\section{ACKNOWLEDGMENTS}

Thank you to the Bali State Polytechnic in particular the Research and Community Service Unit who has been willing to fund this research through DIPA in Fiscal Year 2019.

\section{REFERENCES}

Bungey, J.H., S.G. Milliard, M.G. Grantham, 2006, Testing of Concrete in Structures: Fourth edition, Taylor \& Francis, New York, USA

Charles J. Hellier, 2003, Handbook of Nondestructive Evaluation. Mcgraw Hill, USA

Dilek, U., 2009, Failure, Distress and Repair of Concrete Structures, A Volume in Woodhead Publishing Series in Civil and Structural Engineering Book. Woodhead Publishing Elsevier Ltd., UK

Herlambang, Fajar Surya, Evin Yudhi Setyono, 2017, Pengaruh Jarak Transducer dan Tulangan pada Pengukuran Kedalaman Retak
Beton

Menggunakan

Ultrasonic Pulse Veocity (UPV), Prosiding

SENTRINOV, $23-24$

November 2017, Malang

Malkit, Singh, 2018, Waste and Supplementary Cementitious Materials in Concrete Characterisation, Properties and Applicatiins, A Volume in Woodhead Publishing Series in Civil and Structural Engineering Book, Woodhead Publishing Elsevier Ltd., UK

Riskawati, Nurlina, Rahman, 2018, Alat ukur dan Pengukuran, LPP Unismuh Makasar, Makasar

Sugeng P. Budio, dkk, 2016, Koreksi Pembacaan Ultrasonic Pulse Velocity (UPV) terhadap Kesalahan Akibat Ketidakstabilan Posisi Tranducer, Jurnal Rekayasa Sipil, Vol. 10 No. 1, Universitas Brawijaya, Malang Sujiani, J., 2009, Accuracy Test of Ultrasonic Pulse Velocity (UPV) for Detecting the Crack Depth in Concrete, aMaster Thesis S-2, Department of Civil and Environmental Engineering, Faculty of Engineering, Gajah Mada University 